\title{
Effects of short-term grazing prohibition on soil physical and chemical properties of meadows in Southwest China
}

\author{
Guiqing Zhu Equal first author, 1 , Chaoxiang Yuan Equal first author, ${ }^{1}$, Hede Gong ${ }^{\text {Corresp., } 1}$, Yanling Peng ${ }^{2}$, Changjiang Huang ${ }^{3}$, \\ Chuansheng Wu ${ }^{\text {Corresp., } 3}$, Huachao Duan ${ }^{4}$ \\ ${ }^{1}$ School of Geography and Ecotourism, Southwest Forestry University, Kunming, Yunnan, China \\ 2 Technology Department, Southwest Forestry University, Kunming, Yunnan, China \\ 3 Anhui Province Key Laboratory of Environmental Hormone and Reproduction, Anhui Province Key Laboratory of Embryo Development and Reproductive \\ Regulation, Fuyang Normal University, Fuyang, Anhui, China \\ ${ }^{4}$ College of Forestry, Southwest Forestry University, Kunming, Yunnan, China \\ Corresponding Authors: Hede Gong, Chuansheng Wu \\ Email address: gonghede3@163.com, wwccss521@163.com
}

Background. Grassland plays an important role in the ecosystem, but overgrazing harms the grassland system in many places. Grazing prohibition is an effective method to restore grassland ecosystems, and it plays a great role in realizing the sustainable development of grassland systems. Therefore, it is necessary to carry out research on the influence of regional grazing prohibition on the physical and chemical properties of different grassland systems.

Methods. In Potatso National Park, Southwest China, we selected experimental plots in the artificial grazing meadow area to study the effects of grazing prohibition on plant and soil indexes in subalpine meadows and swamp meadows. We investigated the biomass and species diversity of grazing prohibition treatment and grazing treatment plots and sampled and tested the soil index. The variation percentage was used to remove the original heterogeneity and yearly variation, allowing us to compare differences in plant index and soil index values between grazing prohibition and grazing treatments.

Results. Grazing prohibition increased the aboveground biomass, total biomass, total meadow coverage, average height, richness index, Shannon diversity index and evenness index and reduced the belowground biomass and root/shoot ratio in the subalpine meadow and swamp meadow. Additionally, grazing prohibition reduced the $\mathrm{pH}$ and soil bulk density and increased the soil total carbon, soil organic carbon, soil total nitrogen, soil hydrolyzable nitrogen, soil total phosphorus and soil available phosphorus in the subalpine meadow and swamp meadow. Nonmetric multidimensional scaling (NMDS) analysis showed that both plant indexes and soil indexes were significantly different between grazing and grazing prohibition treatments and between meadow types. Short-term grazing prohibition had a great impact on improving the fertility of meadow soil in the study area. We suggest that long-term and extensive research should be carried out to promote the restoration and sustainable development of regional grassland systems. 
1

2 Effects of Short-term Grazing Prohibition on Soil

3 Physical and Chemical Properties of Meadows in 4 Southwest China

6 Guiqing Zhu Equal first author, 1, Chaoxiang Yuan Equal first author, 1, Hede Gong1, Yanling Peng 2 ,

7 Changjiang Huang ${ }^{3}$, Chuansheng $\mathrm{Wu}^{3}$, Huachao Duan ${ }^{4}$

$9{ }^{1}$ School of Geography and Ecotourism, Southwest Forestry University, Kunming, 650224,

10 China

112 Technology Department, Southwest Forestry University, Kunming, 650224, China

$12{ }^{3}$ Anhui Province Key Laboratory of Environmental Hormone and Reproduction, Anhui Province

13 Key Laboratory of Embryo Development and Reproductive Regulation, Fuyang Normal

14 University, Fuyang, 236037, China

$15{ }^{4}$ College of Forestry, Southwest Forestry University, Kunming, 650224, China

Corresponding Author:

Hede Gong $^{1}$

300 Bailong temple, Panlong district, Kunming, Yunnan, 650224, China

Email address:gonghede3@163.com

Chuansheng $\mathrm{Wu}^{3}$

100 Qinghe Rd, Fuyang, Anhui, 236037, China

E-mail address: wwccss521@163.com

\section{Abstract}

Background. Grassland plays an important role in the ecosystem, but overgrazing harms the grassland system in many places. Grazing prohibition is an effective method to restore grassland ecosystems, and it plays a great role in realizing the sustainable development of grassland systems. Therefore, it is necessary to carry out research on the influence of regional grazing prohibition on the physical and chemical properties of different grassland systems.

Methods. In Potatso National Park, Southwest China, we selected experimental plots in the artificial grazing meadow area to study the effects of grazing prohibition on plant and soil indexes in subalpine meadows and swamp meadows. We investigated the biomass and species 
34 diversity of grazing prohibition treatment and grazing treatment plots and sampled and tested the soil index. The variation percentage was used to remove the original heterogeneity and yearly variation, allowing us to compare differences in plant index and soil index values between grazing prohibition and grazing treatments.

Results. Grazing prohibition increased the aboveground biomass, total biomass, total meadow coverage, average height, richness index, Shannon diversity index and evenness index and reduced the belowground biomass and root/shoot ratio in the subalpine meadow and swamp meadow. Additionally, grazing prohibition reduced the $\mathrm{pH}$ and soil bulk density and increased the soil total carbon, soil organic carbon, soil total nitrogen, soil hydrolyzable nitrogen, soil total phosphorus and soil available phosphorus in the subalpine meadow and swamp meadow. Nonmetric multidimensional scaling (NMDS) analysis showed that both plant indexes and soil indexes were significantly different between grazing and grazing prohibition treatments and between meadow types. Short-term grazing prohibition had a great impact on improving the fertility of meadow soil in the study area. We suggest that long-term and extensive research should be carried out to promote the restoration and sustainable development of regional grassland systems.

Key words: No grazing, Plant and soil indexes, Meadow types, NMDS.

\section{Introduction}

Grassland occupies 1/3 of the global land area (Houghton, 1994) and is a major foundation for the development of animal husbandry in many countries; however, grassland resources are facing tremendous pressure with continuous animal husbandry expansion. Previous studies have shown that overgrazing changes surface vegetation and soil nutrient cycling (Smoliak, Dormaar $\&$ Johnson, 1972; Chaneton \& Lavado, 1996) and can even cause permanent degradation of grassland productivity and ecosystem destruction (Su et al., 2004). Therefore, researchers have conducted a wide range of studies on the impact of grazing on grassland degradation from multiple angles. These include soil nutrients (Jeddi \& Chaieb, 2010; Xiong et al., 2014; Ma, Ding \& Li, 2016; Li et al., 2016), vegetation (Zhao et al., 2009; Jeddi \& Chaieb, 2010; Cheng et al., 2011; Niu et al., 2018) and soil structure (Li et al., 2011b; Jaweed, Saptarshi \& Gaikwad, 2012; Mofidi et al., 2012). China has a grassland area of $4.32 \times 10^{6} \mathrm{~km}^{2}$, which accounts for $40 \%$ of the country's land area (Tong, Zhao \& Wu, 2018), and 90\% of grasslands have been degraded to varying degrees. The degradation trend continues to increase (Ren et al., 2007; Cao et al., 2013). Grazing prohibition is considered an effective way to prevent vicious grassland degradation cycles and restore grassland ecosystems and soil fertility (Wu et al., 2014; Bi et al., 2018). Therefore, it is necessary to carry out grazing prohibition work in grassland areas to protect grassland resources and maintain ecological balance. 
Studies have found that the plant index is significantly correlated with grazing pressure (Larreguy, Carrera \& Bertiller, 2017), and grazing prohibition can significantly increase aboveground and belowground biomass (Cheng et al., 2011; Wu et al., 2014; Xiong et al., 2014; Li et al., 2016), plant coverage, plant richness (Pei, Fu \& Wan, 2008; Cheng et al., 2011; Chen \& Tang, 2016), total biomass, and average height (Pei, Fu\& Wan, 2008). This may be attributed to the grazing prohibition hindering external disturbance activities, protecting the grassland crust structure, and providing opportunities for vegetation growth and reproduction. Moreover, grazing prohibition significantly reduces the root/shoot ratio, Shannon diversity index and evenness (Wang et al., 2014). This is caused by rapid growth of the aboveground parts of the vegetation and the consumption of root nutrient reserves. Grazing prohibition has a protective effect on dominant species, and the constructive species compete for space and nutrients and crowd out other dwarf species. However, studies have also found that grazing prohibition had no

Dormaar \& Johnson, 1972).

Studies have shown that grazing prohibition significantly reduces $\mathrm{pH}(\mathrm{Pei}, \mathrm{Fu} \& \mathrm{Wan}, 2008 ; \mathrm{Wu}$ et al., 2010; Wang et al., 2014). This is likely due to grazing prohibition blocking livestock manure and urine input, and dominant species development makes saline-loving vegetation expansion difficult. Meanwhile, grazing prohibition eliminates the soil compaction process caused by livestock trampling and reduces soil bulk density (Hiernaux et al., 1999; Pei, Fu \& Wan, 2008; Wu et al., 2010; Wang et al., 2014). Some studies have also found that grazing prohibition can increase, decrease, or not significantly affect soil $\mathrm{pH}$ and soil bulk density because of study area differences (Moussa, Rensburg \& Kellner, 2009; Lu et al., 2015). Furthermore, grazing prohibition can effectively increase soil organic carbon and soil total nitrogen (Wu et al., 2008; Xiong et al., 2014; Lu et al., 2015; Li et al., 2016), soil total phosphorus and soil available phosphorus (Hiernaux et al., 1999; Li et al., 2011b; Ma, Ding \& Li, 2016) because grazing prohibition can largely compensate for soil index losses caused by overgrazing and restore soil ecological indicators in pastoral areas (Raiesi \& Riahi, 2014). Studies have found that the effect of grazing prohibits on soil organic carbon (Moussa, Rensburg $\&$ Kellner, 2009) and available phosphorus (Lu et al., 2015) without a significant increase or decrease. The same soil index has different responses to grazing prohibition and is related to the terrain, species composition, climate and precipitation of the study area (Wu et al., 2010; Xiong et al., 2014; Zhang et al., 2018).

In summary, the grazing prohibition effects on grassland plant and soil indexes are unclear, and 
it is necessary to carry out grazing prohibition experiments in more meadow areas to identify the influential mechanism. Meadows, as an important part of grasslands, require strengthened realtime monitoring of degraded areas and carry out grazing prohibition for sustainable development. Subalpine meadow and swamp meadow ecosystems are typical grasslands in Potatso National Park (Wang, Zhong \& Yang, 2000); however, nomadic customs have caused degradation in park grasslands. Carrying out this research is an effective means to deeply understand the impact on soil and plant indexes by grazing prohibition in Potatso National Park, and can provide scientific guidance for regional grassland protection and future development.Therefore, we assume that grazing prohibition has a positive effect on the plant and soil indexes of subalpine meadows and swampy meadows. To verify this hypothesis, we conducted grazing and grazing prohibition experiments in the subalpine and swampy meadow pastoral areas of Potatso National Park to determine the effect of grazing prohibition on improving plant and soil indexes.

\section{Materials \& Methods}

\section{Site description}

The study is located in Potatso National Park $\left(27^{\circ} 55^{\prime} 3^{\prime \prime} \mathrm{N}, 9^{\circ} 56^{\prime} 33^{\prime \prime} \mathrm{E} ; 3,601 \mathrm{~m}\right.$ above sea level) in Shangri-La County, Diqing Tibetan Autonomous Prefecture, northwestern Yunnan, China(Fig. 1A). According to long-term meteorological monitoring data, the annual average temperature is $5.4^{\circ} \mathrm{C}$, the hottest monthly average temperature is $13.2^{\circ} \mathrm{C}$, and the coldest monthly average temperature is $-3.8^{\circ} \mathrm{C}$. The average annual precipitation is $619.9 \mathrm{~mm}$, and the summer and autumn precipitation accounts for $80 \%$ to $90 \%$ of the annual precipitation, respectively (JuneSeptember) (Tang \& Yang, 2014; He et al., 2019). The soil is mainly dark brown soil, and the bare bedrock on the surface is mostly mica schist with crystalline limestone (Li et al., 2013). The area is rich in animal and plant resources, including 279 species of vertebrates, 67 species of mammals, 171 species of birds, and 13 species of amphibians. The vegetation includes 6 vegetation types, 11 vegetation subtypes, 34 communities, and more than 2,000 wild seed plants (Wang, Zhong \& Yang, 2000). The vegetation types of subalpine meadows and swamp meadows are both alpine meadows (Li et al., 2020). In the subalpine meadow experimental area, Blysmus sinocompressus is the dominant species in the community, and the community species composition includes Blysmus sinocompressus, Carex muliensis, Polygonum viviparum, Potentilla griffithii, Potentilla stenophylla, Stellera chamaejasme, Aletris pauciflora, Gentiana crassula, Veratrilla baillonii and Gentiana wardii. In the swamp meadow experimental area, Blysmus sinocompressus is the dominant species in the community too, and the community species composition includes Blysmus sinocompressus, Carex muliensis, Polygonum viviparum, Potentilla griffithii, Parnassia delavayi, Adonis brevistyla, Plantago depressa, Elsholtzia ciliata, 
142

143

144

145

146

147

148

149

150

151

152

153

154

155

156

157

158

159

160

161

162

163

164

165

166

167

168

169

170

171

172

173

174

175

176

177

Primula sinopurpurea, Agrimonia pilosa, Prunella vulgaris.

\section{Experimental design}

With reference to a previous experimental research design, a similar experimental design was adopted in Potatso National Park to carry out the grazing prohibition experiment ( Wu et al., 2010; Wang et al., 2014; Lu et al., 2015; Chen \& Tang, 2016). In Potatso National Park, typical subalpine meadow and swamp meadow were selected, and six $5 \mathrm{~m} \times 5 \mathrm{~m}$ plots were randomly selected in both subalpine meadow and swamp meadow types. The distance between plots in the same meadow types was $2 \mathrm{~m}$ (Fig. 1B). In the subalpine meadow, three plots surrounded by barbed wire fence were used for the grazing prohibition treatment, and three grazing treatment plots were randomly selected from free grazing areas; we used the same method to set up the experimental plots in the swamp meadow as in the subalpine meadow. In this experiment, the grazing plots were perennial grazing plots with a grazing history of more than 100 years, and the grazing animals were yaks and horses. The grazing prohibition plots were short-term complete grazing prohibition plots, and the grazing prohibition period was 1 year (September 2019September 2020). In this study, the grazing pressure was the same for the subalpine meadow and swamp meadow. Every morning, livestock departed from the swamp meadows to the subalpine meadows, passed through the woods, and returned on the same road in the evening, passing through the woods, subalpine meadows and swamp meadows in turn.

After the grazing prohibition treatment (the growth of the aboveground biomass was stable), three $1 \mathrm{~m} \times 1 \mathrm{~m}$ square sampling areas were selected in each of the 12 sample plots, and the aboveground plants were trimmed close to the ground and dried to a constant weight to estimate the aboveground biomass. Three $50 \mathrm{~cm} \times 50 \mathrm{~cm} \times 20 \mathrm{~cm}$ soil samples were taken from each experimental plot, three repeated samples from each plot were dried to constant weight, and the average value was taken to estimate the belowground biomass in every plot. The sampling point distance was greater than $1 \mathrm{~m}$, and foreign matter (soil and stones) was washed and removed. An earth-boring drill (diameter $3.8 \mathrm{~cm}$, volume $100 \mathrm{~cm} 3$ ) was used sample the following soil layers: 0-10 cm, 10-20 cm, 20-30 cm, 30-40 cm, and 40-60 cm (note: at $60 \mathrm{~cm}$, the drill reached the rock layer and further sampling could not be performed). We sampled 3 random sites in an area of approximately $1 \mathrm{~m} \times 1 \mathrm{~m}$, mixed the same soil layer samples taken from 3 sampling sites, sealed them and sent them to the laboratory for air drying and root removal treatment. Then, the samples were analyzed for $\mathrm{pH}$, soil bulk density, soil total carbon, soil organic carbon, soil total nitrogen, soil hydrolyzable nitrogen, soil total phosphorus and soil available phosphorus. In each treatment plot, three $1 \mathrm{~m} \times 1 \mathrm{~m}$ square areas were delineated along the diagonal from the upper left corner, the middle, and the lower right corner to investigate the plant index, and the collected 
178 specimens were brought back to the laboratory for identification.

179

180

181

182

183

184

185

186

187

188

189

190

191

192

193

194

195

196

197

198

199

200

201

202

203

204

205

206

207

208

209

210

\section{Data collection and calculations}

The calculation formulas for the meadow community richness index, Shannon diversity index and evenness index in the state of grazing prohibition and free grazing in subalpine meadows and swamp meadows are as follows (Wu et al., 2009; Wang et al., 2014):

Richness index (R):

$R=S$

Shannon diversity index $(\mathrm{H})$ :

$H=-\sum_{i=1}^{S}(P i \ln P i)$

Evenness index (E):

$E=\frac{H}{\ln S}$

where $\mathrm{S}$ is the total number of species in the meadow community per unit area and $\mathrm{Pi}$ is the proportion of the species in the total species.

Field experiment plots are prone to differences. To remove the original heterogeneity and yearly variation, we calculated the variation percentage $(V, \%)$ of the soil indexes and plant indexes with the following formula:

$V_{i}=\left(\frac{\text { Final }}{\text { Initial }}-1\right) \times 100 \%$

where $\mathrm{i}$ refers to the soil indexes and plant indexes. To calculate the grazing prohibition effects $(G P E)$, the formula was as follows:

$G P E_{i}=V_{i g p}-V_{i g}$

where gp refers to grazing prohibition and $g$ refers to grazing.

Then, the $V_{\mathrm{i}}$ between grazing and grazing prohibition in each meadow type was tested by the $\mathrm{t}$ test or Wilcox test (when data were not normally distributed). Nonmetric multidimensional scaling (NMDS) was used to simplify the meadow types and grazing treatment samples to a lowdimensional space for positioning, analysis and classification while retaining the original relationship between the objects. All data are expressed as the mean \pm standard deviation (Mean $\pm \mathrm{SD}$ ), and all statistical tests and figure drawing were performed using R software and Rstudio ( $\mathrm{R}$ version 4.0.3 for Windows, using packages readxl, ggplot2, ggpubr and vegan).

\section{Results}

\section{Effects of grazing prohibition on plant indexes}


211 In the subalpine meadow, grazing prohibition significantly increased aboveground biomass $(p<$ 2120.001 ; Fig. 2A), total meadow coverage ( $p<0.01$; Fig. 2E) and average height $(p<0.001$; Fig. $2132 \mathrm{~F}$ ) by $324.96,25.35$ and $225.56 \%$, respectively, and the total biomass, richness index, Shannon 214 diversity index and evenness index increased by $17.51,16.67,20.62$ and $11.05 \%$, respectively, 215 but without statistical significance (Figs. 2C, 2G, 2H \& 2I). However, grazing prohibition 216 significantly reduced the root/shoot ratio by $101.65 \%(p<0.001$; Fig. 2D), while the reduction in 217 belowground biomass, at 22.07\%, was not significant (Fig. 2B).

218

In the swamp meadow, grazing prohibition significantly increased the aboveground biomass $(p<$ 0.001; Fig. 2A), total biomass ( $p<0.01$; Fig. 2C), total meadow coverage, average height, Shannon diversity index and evenness index ( $p<0.05$; Figs. $2 \mathrm{E}, 2 \mathrm{~F}, 2 \mathrm{H} \& 2 \mathrm{I})$, and these values increased by $283.92,79.99,4.27,132.79,72.89$ and $54.15 \%$, respectively. The richness index increased by $26.98 \%$ but without statistical significance (Fig. 2G). Grazing prohibition significantly reduced the root/shoot ratio by $54.20 \%(p<0.001$; Fig. 2D), but the reduction in belowground biomass of $11.54 \%$ was not significant (Fig. 2B).

NMDS analysis showed that plant indexes between grazing and grazing prohibition were significantly different (stress $=0.097$ ), and those between meadow types were not different (Fig. 3A).

\section{Effect of grazing prohibition on soil indexes}

In the subalpine meadow, grazing prohibition reduced the $\mathrm{pH}$ by 0.70 to $1.53 \%$ (Fig. $4 \mathrm{~A}$ ) and the soil bulk density by 3.91 to $15.95 \%$ (Fig. 4B). Grazing prohibition increased the soil total carbon, soil organic carbon, soil total nitrogen, soil hydrolyzable nitrogen, soil total phosphorus and soil available phosphorus (Figs. 5A, 5B, 6A, 6B, 7A \& 7B), and these values increased by 2.02 to $28.93 \%, 2.10$ to $16.35 \%, 1.09$ to $11.66 \%, 3.35$ to $13.03 \%, 0.64$ to $5.36 \%$ and 0.17 to $3.74 \%$, respectively. In addition, the increases in soil total carbon and soil organic carbon were significant in the $0-20 \mathrm{~cm}$ and $10-20 \mathrm{~cm}$ layers ( $p<0.05$; Figs. 5A \& 5B), respectively. The other parameters were not significantly different between grazing and grazing prohibition treatments.

In the swamp meadow, grazing prohibition reduced the $\mathrm{pH}$ and soil bulk density by 1.06 to $2.70 \%$ and 2.22 to $6.87 \%$ (Figs. 4A \& 4B), respectively. Grazing prohibition increased the soil total carbon, soil organic carbon, soil hydrolyzable nitrogen, soil total phosphorus, soil available phosphorus and 0-30 cm soil total nitrogen (Figs. 5A, 5B, 6A, 6B, 7A \& 7B), and these values increased by 25.91 to $117.23 \%, 9.02$ to $48.30 \%, 19.61$ to $71.80 \%, 8.30$ to $40.50 \%, 17.51$ to $52.87 \%$ and 8.26 to $30.85 \%$, respectively. The increases were significant for soil total carbon $(p$ 
$247<0.05$ and 0.01$)$, soil hydrolyzable nitrogen and soil available phosphorus at 0-60 $\mathrm{cm}(p<0.05$, 2480.01 and 0.001$)$; soil organic carbon at 10-40 $\mathrm{cm}(p<0.05)$; and soil total phosphorus at 20-40 $249 \mathrm{~cm}(p<0.01$ and 0.001$)$.

250

NMDS analysis showed that the soil index values were significantly different between grazing and grazing prohibition sites (stress $=0.178$ ) but that the soil index values were not different between meadow types and among soil depths (Fig. 3B).

\section{Discussion}

Grazing prohibition is an effective means to improve grassland vegetation parameters (Pei, Fu \& Wan, 2008; Cheng et al., 2011; Chen \& Tang, 2016; Li et al., 2016). In our study, grazing prohibition treatments increased the aboveground biomass, total biomass, total meadow coverage, average height, richness index, Shannon diversity index and evenness index in both the subalpine meadow and swamp meadow (Figs. 2A, 2C, 2E, 2F, 2G, 2H \& 2I), consistent with the results of other studies (Jeddi \& Chaieb, 2010; Cheng et al., 2011; Chen \& Tang, 2016; Oñatibia, Boyero \& Aguiar, 2018). This may be because the grazing prohibition treatment protected vegetation from gnawing and trampling by livestock, there more grass when livestock disturbance was reduced ( $W u$ et al., 2010). Our grazing prohibition experiment reduced the belowground biomass (Fig. 2B), which was different from other research results (Wu et al., 2010; Wu et al., 2014; Li et al., 2016). Previous researchers suggested that the belowground biomass increases may be due to the severe degradation of grassland caused by overgrazing in the study area and that following restoration of grassland vegetation in the grazing prohibition treatment, the vegetation root system became more developed than that prior to the grazing prohibition ( $W u$ et al., 2014). Our results are consistent with other study results (Smoliak, Dormaar \& Johnson, 1972): the decrease may be due to the reduction of external interference and the transfer of soil-derived nutrients from vegetation roots to the aboveground part for growth. In contrast, in the grazing area, vegetation is prone to exhibiting self-protection behavior when threatened by gnawing and trampling and uses nutrients for root growth to guarantee survival (Smoliak, Dormaar \& Johnson, 1972). The grazing prohibition treatment significantly increased aboveground biomass and reduced belowground biomass, which in turn significantly reduced the root/shoot ratio (Fig. 2D). The increase or decrease effect of the plant index after grazing prohibition differed between the meadow types (Fig. 3A), and this difference was mainly driven by the different meadow types and species compositions (Milchunas, Lauenroth \& Burke, 1998; Qiu et al., 2013; Wang et al., 2014). 
282 Grazing prohibition reduced $\mathrm{pH}$ and soil bulk density (Figs. 4A \& 4B), which was consistent 283 with other research results (Smoliak, Dormaar \& Johnson,1972; Hiernaux et al., 1999; Wang et

\section{al., 2014; Ma, Ding \& Li, 2016). This result may be because grazing prohibition treatments} isolate livestock activities, hinder the input of excrement and the impact of livestock trampling. The dominant species supplants saline-loving vegetation and effectively improves the soil structure, thereby reducing $\mathrm{pH}$ and soil bulk density (Pei, Fu \& Wan, 2008; Wang et al., 2014). Grazing prohibition is an effective means to increase soil total carbon, soil organic carbon (Wu et al., 2008; Piñeiro et al., 2009; Wu et al., 2010; Rui et al., 2011), soil total nitrogen (Raiesi \& Riahi, 2014; Xiong et al., 2014; Ma, Ding \& Li, 2016), soil total phosphorus and soil available phosphorus (Hiernaux et al., 1999; Li et al., 2011b; Ma, Ding \& Li, 2016). In our study, the grazing prohibition treatment increased soil total carbon, soil organic carbon, soil total nitrogen, hydrolyzable nitrogen, soil total phosphorus and soil available phosphorus in both the subalpine meadow and swamp meadow (Figs. 5A, 5B, 6A, 6B, 7A \& 7B), which was consistent with most research findings (Pei, Fu \& Wan, 2008; Lu et al., 2015; Li et al., 2016; Ma, Ding \& Li, 2016). Some values of these soil indexes show significant differences between the grazing prohibition and grazing treatments, such as 0-20 cm soil total carbon (Fig. 5A; $p<0.05$ ) and 10-20 cm soil organic carbon (Fig. 5B; $p<0.05$ ) in the subalpine meadow and $0-60 \mathrm{~cm}$ total soil carbon (Fig. $5 \mathrm{~A} ; p<0.05$ ), 10-40 cm soil organic carbon (Fig. 5B; $p<0.05$ ), 0-60 cm hydrolyzable nitrogen (Fig. 6B; $p<0.05$ ), 20-40 cm soil total phosphorus (Fig. 7A; $p<0.01$ ) and 0-60 cm soil available phosphorus (Fig. 7B; $p<0.05$ ) in the swamp meadow. Some of these differences are significant at the $p<0.001$ level. These soil index changes may be due to the grazing prohibition treatment compensating for the loss caused by grazing (Fuhlendorf et al., 2002; Raiesi \& Riahi, 2014; Larreguy, Carrera \& Bertiller, 2014). The grazing prohibition treatment reduced the soil total nitrogen in the swamp meadow at 30-60 cm and may be related to the higher soil gravel content of the soil layer $(30-60 \mathrm{~cm})$ in the swamp meadow.

Through comparison, grazing time and grazing intensity have a significant impact on plant diversity and community structure (Niu et al., 2018), mainly due to the removal of plants by animal gnawing and trampling (Wen et al., 2013; Wang et al., 2014). Previous studies have shown that light and moderate grazing can effectively restore the richness index and Shannon diversity index in degraded grasslands, while overgrazing reduces these indexes (Zhao et al., 2009). Light grazing increases the plant coverage (Li et al., 2011a; Larreguy, Carrera \& Bertiller, 2014), richness index (Niu et al., 2018; Oñatibia, Boyero \& Aguiar, 2018), total biomass (Niu et al., 2017), aboveground biomass and plant height (Li et al., 2011a). This likely occurs because light grazing represents a reduction in livestock gnawing and trampling, reduces livestock destruction of the grass crust, and provides dwarf and more disturbed species greater chances of survival. Simultaneously, light grazing also reduces belowground biomass and the root/shoot ratio (Li et al., 2011a), which can be attributed to the adaptive response of grassland 
320 vegetation to changes in grazing pressure. Long-term grazing prohibition can effectively improve 321 the characteristics of grassland communities (Cheng et al., 2011). Study results from the Alxa 322 Desert indicated that the plant coverage, grass height, and aboveground biomass increased by 47.55, 109.77 and 58.51\%, respectively, at six-year prohibition sites. The increases at the twoyear prohibition sites were $21.99,89.19$ and $9.57 \%$, respectively (Pei, Fu \& Wan, 2008), and these increases were higher than those at the grazing sites. A study in southern Tunisia produced analogous results: a twelve-year grazing prohibition treatment allowed the plant coverage to increase by 2 times relative to grazed sites, with a percentage increase of $71.3 \%$, and the aboveground biomass was 3 and 3.4 times higher in six-year and twelve-year prohibition sites, respectively, than that at grazed sites (Jeddi \& Chaieb, 2010). Obviously, differences in the study area, grazing prohibition history, and grazing intensity result in different effects.

Grazing pressure has a large effect on soil indexes, and livestock damage and excrement can easily lead to soil salinization, which in turn increases the spread of saline-loving plant communities and leads to increases in soil pH (Wu et al., 2010; Wang et al., 2014). Livestock trampling causes soil compaction (Hiernaux et al., 1999), which greatly increases soil bulk density (Mofidi et al., 2012). Long-term (nine-year) grazing prohibition significantly altered soil properties, and the $\mathrm{pH}$ and soil bulk density were reduced by 6.53 and $30.23 \%$ when compared with the grazing treatment ( $W u$ et al., 2010). This value was higher than our results (Figs. 4A \& 4B), likely due to the effects of grazing prohibition history. The Alxa Desert steppe results illustrate that the soil buck density decreased by 4.08 to $5.33 \%$ and 3.27 to $5.52 \%$ at the six-year and two-year prohibition sites, respectively, and the $\mathrm{pH}$ decreased by 2.45 to $3.21 \%$ and 1.35 to $2.24 \%$, respectively ( $P e i, F u \& W a n, 2008$ ). There were differences in the reduction, and our results may be due to differences in the meadow types, grazing prohibition histories, grazing intensities, species compositions and initial index values. In this study, the mean increase in soil total carbon (11.73\%) in the subalpine meadow was less than the value of $17 \%$ observed in the Zagros Mountains in central Iran (Raiesi \& Riahi, 2014) (Fig. 5A), and the mean increase in soil organic carbon $(6.32 \%)$ was also lower than the value of $13.9 \%$ observed in the Hulunbuir grassland (Wu et al., 2014) and the value of $22 \%$ observed in the Alxa Desert grasslands after six years of grazing prohibition (Pei, Fu\& Wan, 2008) (Fig. 5B). However, the mean increases in the swamp meadow's soil total carbon $(83.29 \%)$ and soil organic carbon $(25.03 \%)$ were obviously higher than those observed in these other studies (Figs. 5A \& 5B). Except for individual soil depths, the grazing prohibition experiment effect on the mean increases in soil total nitrogen in the subalpine meadow $(6.72 \%)$ and swamp meadow $(7.56 \%)$ was weaker than the values observed by Pei et al., (2008), i.e.,14\%, Raiesi and Riahi (2014), i.e., 19\%, and Ma, Ding \& Li (2016), i.e., 27.4\% (Fig. 6A). Moreover, different conclusions were reached regarding the impact of grazing prohibition on soil total phosphorus and soil available phosphorus. Li et al. (2011a) concluded that light grazing can reduce soil total phosphorus and soil available phosphorus, but most research results have shown that grazing prohibition increases soil total phosphorus and soil available phosphorus (Hiernaux et al., 1999; Li et al., 2011b; Ma, Ding \& Li, 2016). Studies have also found that grazing prohibition reduces soil total phosphorus (Lu et al., 
3612015 ) or has no effect (Li et al., 2018) and has no effect on soil available phosphorus (Lu et al.,

362 2015). In our study, grazing prohibition increased the soil total phosphorus and soil available

363 phosphorus in the subalpine meadows and swamp meadows (Figs. 7A \& 7B). Through our

364 experiments, we also found that the effects of grazing prohibition on soil indexes were different

365 among different meadow types (Fig. 3B). This result also showed that the grazing prohibition

366 area and time length were different, which led to the different effects of the grazing prohibition

367 treatment on the soil indexes.

Our research results differed between the two meadow types (Figs. 3A \& 3B), and there was also a certain difference between the research results from different regions. This difference may be affected by the terrain (Zhang et al., 2018), soil structure (Jaweed, Saptarshi \& Gaikwad, 2012), surface species (Wu et al., 2010; Wang et al., 2014) and natural precipitation conditions (Xiong et al., 2014). Our results suggested that short-term grazing prohibition played a positive role in the plant and soil indexes in the free grazing area of Potatso National Park. The grazing prohibition effects were weaker than those of long-term treatments, and the results also showed that we need to carry out long-term experimental research in the region. In short, overgrazing is unconducive to the physical and chemical properties of soil and the sustainable development of surface vegetation, and grazing prohibition is beneficial for improving plant and soil indexes (Bi et al., 2018). Scientific and effective management have the potential reverse this degradation. While improving soil fertility, grazing prohibition also protects regional species diversity. In addition, we suggest carrying out rotation grazing and nitrogen deposition experiments in degraded areas to better utilize the value of limited grassland resources.

\section{Conclusions}

This study's main purpose was to evaluate the effectiveness of a grazing prohibition treatment on restoring degraded areas in the free pasture area of the subalpine meadow and marsh swamp ecosystems in Potatso National Park, China. We used plant and soil indicators as the main research objects. According to the experimental results, we found that the grazing prohibition treatment was effective in restoring the surface plant index, and it increased the aboveground biomass, total biomass, total meadow coverage, average height, richness index, Shannon diversity index and evenness index in both subalpine meadows and swamp meadows. In contrast, it reduced the belowground biomass and root/shoot ratio. There were differences between meadow types, but the grazing prohibition effect was more important. Meanwhile, the grazing prohibition treatment improved the soil index, reduced the $\mathrm{pH}$ and soil bulk density, and increased the soil total carbon, soil organic carbon, soil total nitrogen, soil hydrolyzable nitrogen, soil total phosphorus and soil available phosphorus in the subalpine meadow and swamp 
397

398

399

400

401

402

403

404

405

406

407

408

409

410

411

412

413

414

415

416

417

418

419

420

421

422

423

424

425

426

427

428

429

430

meadow. NMDS analysis showed that different meadow types and soil depths had an impact on the soil index, but the impact was less than that of the grazing prohibition treatment.

\section{Acknowledgments}

This work is a research contribution from Potatso National Park for Meadows Ecosystem Studies.

\section{References}

Bi X, Li B, Fu Q, Fan Y, Ma LX,Yang ZH, Nan B, Dai XH, Zhang XS. 2018. Effects of grazing exclusion on the grassland ecosystems of mountain meadows and temperate typical steppe in a mountain-basin system in Central Asia's arid regions, China. Science of The Total Environment 630(15):254-263 DOI: 10.1016/j.scitotenv.2018.02.055.

Cao J, Yeh ET, Holden NM, Qin Y, Ren Z. 2013. The Roles of Overgrazing, Climate Change and Policy As Drivers of Degradation of China's Grasslands. Nomadic Peoples 17(2):82-101 DOI: $10.3167 / \mathrm{np} .2013 .170207$.

Chaneton EJ, Lavado RS. 1996. Soil nutrients and salinity after long-term grazing exclusion in a Flooding Pampa grassland. Rangeland Ecology \& Management 49(2): 182-187 DOI: $10.2307 / 4002692$.

Chen J, Tang HP. 2016. Effect of Grazing Exclusion on Vegetation Characteristics and Soil Organic Carbon of Leymus chinensis Grassland in Northern China. Sustainability 8(1):56 DOI: $10.3390 / \mathrm{su} 8010056$.

Cheng J,Wu GL,Zhao LP,Li Y,Li W,Cheng JM. 2011. Cumulative effects of 20-year exclusion of livestock grazing on above- and belowground biomass of typical steppe communities in arid areas of the Loess Plateau, China. Plant Soil and Environment 57(1):4044 DOI: 10.17221/153/2010-PSE.

Fuhlendorf SD, Zhang HL, Tunnell TR, Engle DM, Cross AF. 2002. Effects of Grazing on Restoration of Southern Mixed Prairie Soils. Restoration Ecology 10(2):401-407 DOI: 10.1046/j.1526-100X.2002.00013.x.

He SQ, Li W, Cheng XP, Tan R, Song WH. 2019. The effect of trampling disturbance on functional traits, species diversity, and functional diversity of alpine meadows in Bitahai Nature Reserve. Acta Ecologica Sinica 39(6):2063-2070 DOI: 10.5846 / stxb201803300657.

Hiernaux P, Bielders CL, Valentin C, Bationo A, Fernández-Rivera S. 1999. Effects of livestock grazing on physical and chemical properties of sandy soils in Sahelian rangelands. Journal of Arid Environments 41(3):231-245 DOI: 10.1006/jare.1998.0475. 
431 Houghton RA. 1994.The Worldwide Extent of Land-Use Change. BioScience 44(5):305-313 DOI: $10.2307 / 1312380$.

Jaweed TH, Saptarshi PG, Gaikwad SW. 2012. Grazing Response of Topsoil Characteristics in Temperate Rangelands of Kashmir, Himalaya. RANGELAND JOURNAL 2(3):583-590. (This article has no DOI)

Jeddi K, Chaieb M. 2010. Changes in soil properties and vegetation following livestock grazing exclusion in degraded arid environments of South Tunisia. Flora 205(3):184-189 DOI: 10.1016/j.flora.2009.03.002.

Larreguy C, Carrera AL, Bertiller MB. 2014. Effects of long-term grazing disturbance on the belowground storage of organic carbon in the Patagonian Monte, Argentina. Journal of Environmental Management 134(15):47-55 DOI: 10.1016/j.jenvman.2013.12.024.

Larreguy C, Carrera AL, Bertiller MB. 2017. Reductions of plant cover induced by sheep grazing change the above-belowground partition and chemistry of organic $\mathrm{C}$ stocks in arid rangelands of Patagonian Monte, Argentina. Journal of Environmental Management 199:139-147 DOI: 10.1016/j.jenvman.2017.04.086.

Li G, Zhang Z, Shi LL, Zhou Y, Yang M, Cao JX, Wu SH, Lei GC. 2018. Effects of Different Grazing Intensities on Soil C, N, and P in an Alpine Meadow on the QinghaiTibetan Plateau, China. International Journal of Environmental Research \& Public Health 15(11): 2584 DOI: 10.3390/ijerph15112584.

Li HM, Yu QG, Li NY, Wang J, Yang YM. 2013. Study on Landscape Dynamics and Driving Mechanisms of the Shudu Lake Catchment Wetlands in Northwest Yunnan. Journal of West China Forestry Science 42(3): 34-39 DOI: 10.16473/j.cnki.xblykx 1972.2013.03.003.

Li HQ, Zhang FW, Mao SJ, Zhu JB, Yang YS, He HD, Li YN. 2016. Effects of Grazing Exclusion on Soil Properties in Maqin Alpine Meadow, Tibetan Plateau, China. Polish Journal of Environmental Studies 25(4): 1583-1587 DOI: 10.15244/pjoes/62099.

Li W, He SQ, Cheng XP, Zhang GX. 2020. Short-term effects of experimental trampling on alpine grasslands in Shangri-la, China. Global Ecology and Conservation 23: e01161 DOI: 10.1016/j.gecco.2020.e01161.

Li W, Huang HZ, Zhang ZN, Wu GL. 2011a. Effects of grazing on the soil properties and C and $\mathrm{N}$ storage in relation to biomass allocation in an alpine meadow. Journal of soil science \& plant nutrition 11(4): 27-39 DOI: 10.4067/S0718-95162011000400003.

Li YQ, Zhao HL, Zhao XY, Zhang TH, Li YL, Cui JY. 2011b. Effects of grazing and livestock exclusion on soil physical and chemical properties in desertified sandy grassland, Inner Mongolia, northern China. Environmental Earth Sciences 63(4):771-783 DOI: 10.1007/s12665-010-0748-3.

Lu X, Yan Y, Sun J, Zhang X, Chen Y, Wang X, Cheng G. 2015. Short-term grazing 
exclusion has no impact on soil properties and nutrients of degraded alpine grassland in Tibet, China. Solid Earth 7(3):2413-2444 DOI: 10.5194/sed-7-2413-2015.

Ma WM, Ding KY, Li ZW. 2016. Comparison of soil carbon and nitrogen stocks at grazingexcluded and yak grazed alpine meadow sites in Qinghai -Tibetan Plateau, China. Ecological Engineering 87:203-211 DOI: 10.1016/j.ecoleng.2015.11.040.

Milchunas DG, Lauenroth WK, Burke IC. 1998. Livestock Grazing: Animal and Plant Biodiversity of Shortgrass Steppe and the Relationship to Ecosystem Function. Oikos 83(1):65-74 DOI: $10.2307 / 3546547$.

Mofidi M, Rashtbari M, Abbaspour H, Ebadi A, Sheidai E, Motamedi J. 2012. Impact of grazing on chemical, physical and biological properties of soils in the mountain rangelands of Sahand, Iran. Rangeland Journal 34(3):297-303 DOI: 10.1071/RJ11087.

Moussa AS, Rensburg LV, Kellner K. 2009. Soil properties changes after short-term livestock exclusion in "degraded" communally managed rangelands in the western Bophirima District, South Africa. South African Journal of Plant \& Soil 26(2):102-109 DOI: 10.1080/02571862.2009.10639941.

Niu YJ, Yang SW, Wang GZ, Liu L, Du GZ, Hua LM. 2017. Relation between species distribution of plant community and soil factors under grazing in alpine meadow. Chinese Journal of Applied Ecology 28(12): 3891-3898 DOI: 10.13287/j.1001-9332.201712.005.

Niu YJ, Yang SW, Wang GZ, Liu L, Hua LM. 2018. Effects of grazing disturbance on plant diversity, community structure and direction of succession in an alpine meadow on Tibet Plateau, China. Acta Ecologica Sinica 38(3):274-280 DOI: 10.1016/j.chnaes.2017.06.011.

Oñatibia GR, Boyero L, Aguiar MR. 2018. Regional productivity mediates the effects of grazing disturbance on plant cover and patch-size distribution in arid and semi-arid communities. Oikos 127(8) DOI: 10.1111/oik.05104.

Pei SF, Fu H, Wan CG. 2008. Changes in soil properties and vegetation following exclosure and grazing in degraded Alxa desert steppe of Inner Mongolia, China. Agriculture Ecosystems \& Environment 124(1):33-39 DOI: 10.1016/j.agee.2007.08.008.

Piñeiro G, Paruelo JM, Jobbágy EG, Jackson RB, Oesterheld M. 2009. Grazing effects on belowground $\mathrm{C}$ and $\mathrm{N}$ stocks along a network of cattle exclosures in temperate and subtropical grasslands of South America. Global Biogeochemical Cycles 23(2):GB2003 DOI: $10.1029 / 2007 \mathrm{~GB} 003168$.

Qiu LP, Wei XR, Zhang XC, Cheng JM. 2013. Ecosystem Carbon and Nitrogen Accumulation after Grazing Exclusion in Semiarid Grassland. PLoS ONE 8(1):e55433 DOI: 10.1371/journal.pone.0055433.

Raiesi F, Riahi M. 2014. The influence of grazing exclosure on soil C stocks and dynamics, and ecological indicators in upland arid and semi-arid rangelands. Ecological Indicators 41:145- 
154 DOI: 10.1016/j.ecolind.2014.01.040.

Ren H, Shen WJ, Lu HF, Wen XY, Jian SG. 2007. Degraded ecosystems in china: status, causes, and restoration efforts. Landscape \& Ecological Engineering 3(1): 1-13 DOI: 10.1007/s11355-006-0018-4.

Rui YC, Wang SP, Xu ZH, Wang YF, Chen CR, Zhou XQ, Kang XM, Lu SB, Hu YG, Lin QY, Luo CY. 2011. Warming and grazing affect soil labile carbon and nitrogen pools differently in an alpine meadow of the Qinghai-Tibet Plateau in China. Journal of Soils \& Sediments 11(6):903-914 DOI: 10.1007/s11368-011-0388-6.

Smoliak S, Dormaar JF, Johnson A. 1972. Long-Term Grazing Effects on Stipa-Bouteloua Prairie Soils. Journal of Range Management 25(4):246-250 DOI: 10.2307/3896903.

Su YZ, Zhao HL, Zhang TH, Zhao XY. 2004. Soil properties following cultivation and nongrazing of a semi-arid sandy grassland in northern China. Soil \& Tillage Research 75(1):2736 DOI: 10.1016/S0167-1987(03)00157-0.

Tang MY, Yang YX. 2014. Changes in vegetation and soil characteristics under tourism disturbance in lakeside wetland of northwest Yunnan Plateau, Southwest China. Chinese Journal of Applied Ecology 25(5):1283-92 DOI: 10.13287/j.1001-9332.2014.0096.

Tong LG, Zhao B, Wu LM. 2018. Effect of grazing on soil organic carbon fractions and soil physical-chemical properties in desert steppe in Inner Mongolia. Ecology \& Environmental Sciences 27(9):1602-1609 DOI: 10.16258/j.cnki.1674-5906.2018.09.003.

Wang D, Wu GL, Zhu YJ, Shi ZH. 2014. Grazing exclusion effects on above- and belowground $\mathrm{C}$ and $\mathrm{N}$ pools of typical grassland on the Loess Plateau (China). CATENA 123:113120 DOI: 10.1016/j.catena.2014.07.018.

Wang YH, Zhong LS, Yang GH. 2000. Discussion on Exploitation of the Scientific Exploration Tour in the Bita Lake Natural Reserve. Chinese Journal of Ecology 19(2): 64-67 DOI: $10.13292 /$ j.1000-4890.2000.0026.

Wen HY, Niu DC, Fu H, Kang J. 2013. Experimental investigation on soil carbon, nitrogen, and their components under grazing and livestock exclusion in steppe and desert steppe grasslands, Northwestern China. Environmental Earth Sciences 70(7):3131-3141 DOI: 10.1007/s 12665-013-2376-1.

Wu GL, Liu ZH, Zhang L, Chen JM, Hu TM. 2010. Long-term fencing improved soil properties and soil organic carbon storage in an alpine swamp meadow of western China. Plant \& Soil 332(1):331-337 DOI: 10.1007/s11104-010-0299-0.

Wu GL, Du GZ, Liu ZH, Thirgood S. 2009. Effect of fencing and grazing on a Kobresiadominated meadow in the Qinghai-Tibetan Plateau. Plant \& Soil 319:115-126 DO: 10.1007/s11104-008-9854-3.

Wu L, He N, Wang Y, Han X. 2008. Storage and Dynamics of Carbon and Nitrogen in Soil 
after Grazing Exclusion in Leymus chinensis Grasslands of Northern China. Journal of Environmental Quality 37(2):663-668 DOI: 10.2134/jeq2007.0196.

Wu X, Li ZS, Fu BJ, Lu F, Wang DB, Liu HF, Liu GH. 2014. Effects of Grazing Exclusion on Soil Carbon and Nitrogen Storage in Semi-arid Grassland in Inner Mongolia, China. Chinese Geographical Science 24(4):479-487 DOI: 10.1007/s11769-014-0694-1.

Xiong DP, Shi PL, Sun YL, Wu JS, Zhang XZ. 2014. Effects of Grazing Exclusion on Plant Productivity and Soil Carbon, Nitrogen Storage in Alpine Meadows in Northern Tibet, China. Chinese Geographical Science 24(4):488-498 DOI: 10.1007/s11769-014-0697-y. Zhang XY, Liu MZ, Zhao X, Li YQ, Zhao W, Li A, Chen S, Chen SP, Han XG, Huang JH. 2018. Topography and grazing effects on storage of soil organic carbon and nitrogen in the northern China grasslands. Ecological Indicators 93: 45-53 DOI: 10.1016/j.ecolind.2018.04.068.

Zhao HL, Okuro T, Zhou RL, Li YL, Zuo XA, Huang G. 2009. Effects of grazing and climate change on species diversity in sandy grassland,Inner Mongolia, China. Sciences in Cold \& Arid Regions 1(1):30-38 DOI: CNKI:SUN:HAQK.0.2009-01-005. 
Figure 1

Geographical location and our experiment study site.

Geographical location and our experiment study site. Research location (red dot) (A); Grazing prohibition experiment design (B). 


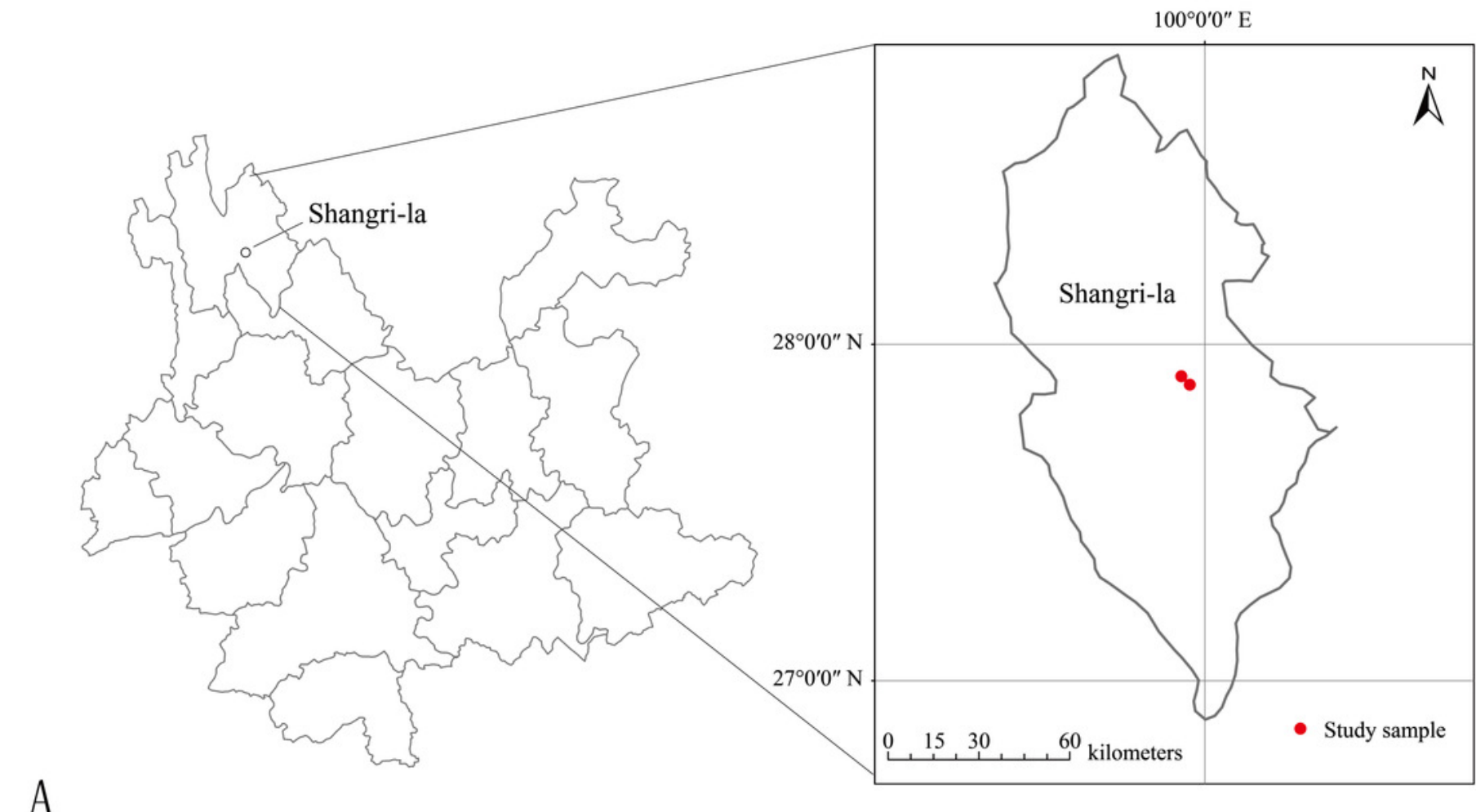

$\overline{\mathrm{B}}$

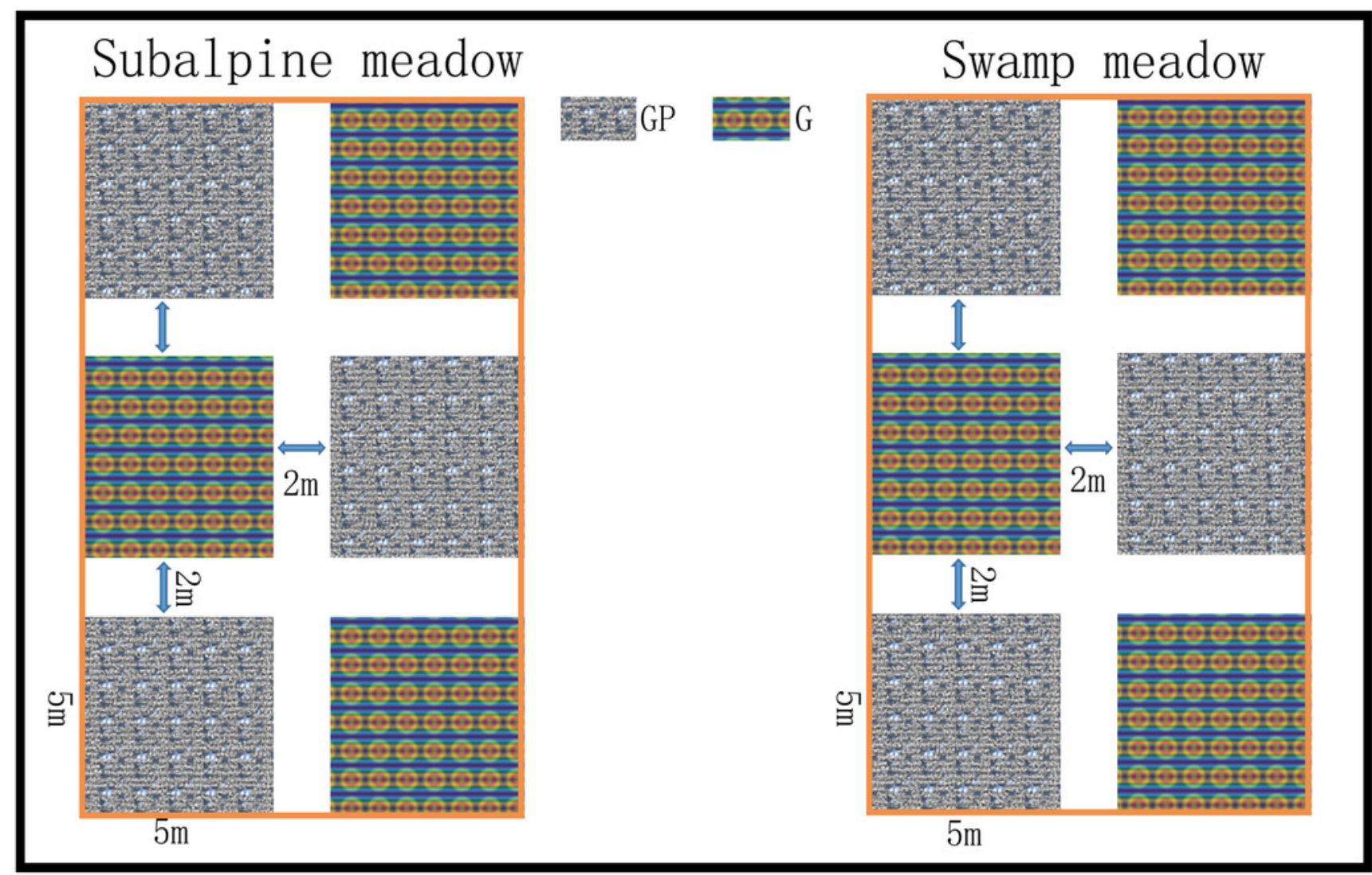




\section{Figure 2}

Effect on plant indexes.

Effect on plant indexes. Above-ground biomass (A), below-ground biomass (B), total biomass $(C)$, root-shoot ratio $(D)$, total meadow coverage $(E)$, average height $(F)$, Richness Index $(G)$, Shannon Diversity Index $(\mathrm{H})$ and Evenness Index $(\mathrm{I})$ in subalpine meadow and swamp meadows between grazing and grazing prohibition treatment. Signifificant differences between grazing and grazing prohibition treatment are indicated by symbols: ${ }^{* *} p<0.001$, ${ }^{* *} p<0.01, * p<0.05$; and no symbol, no signifificant difference. 

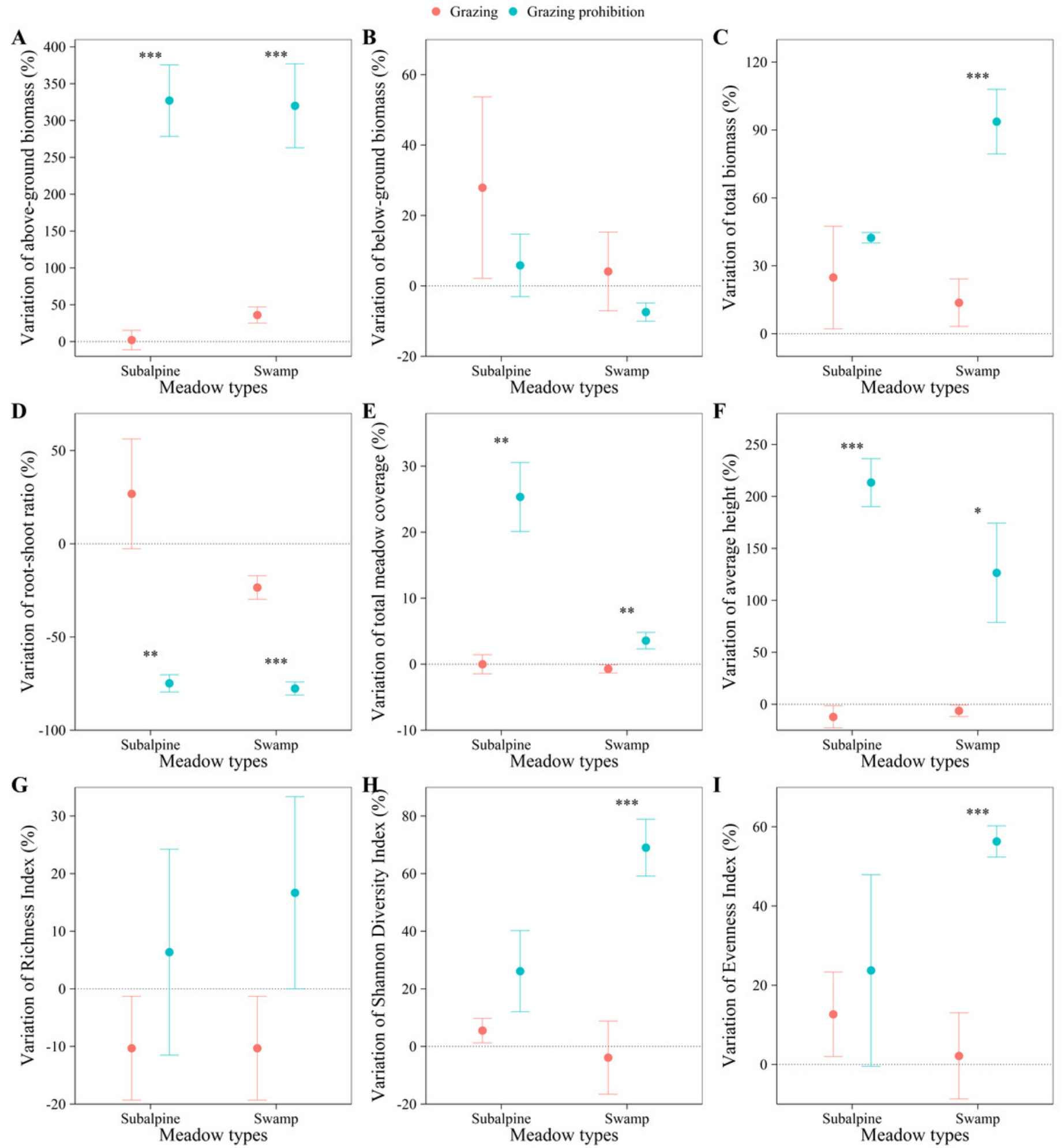


\section{Figure 3}

NMDS analyzes the community structure of plant and soil samples.

NMDS analyzes the community structure of plant and soil samples. Effects on plant community index (A) and soil index (B) in subalpine meadow and swamp meadow between grazing and grazing prohibition treatment. The shape represents meadow types, the color represents different treatments, the soil depth is represented by the size, and the circle represents the $95 \%$ confidence interval of the centroid position of each group. The NMDS analysis is based on Bray-Curtis similarity, and the stress value is shown in the lower right corner.
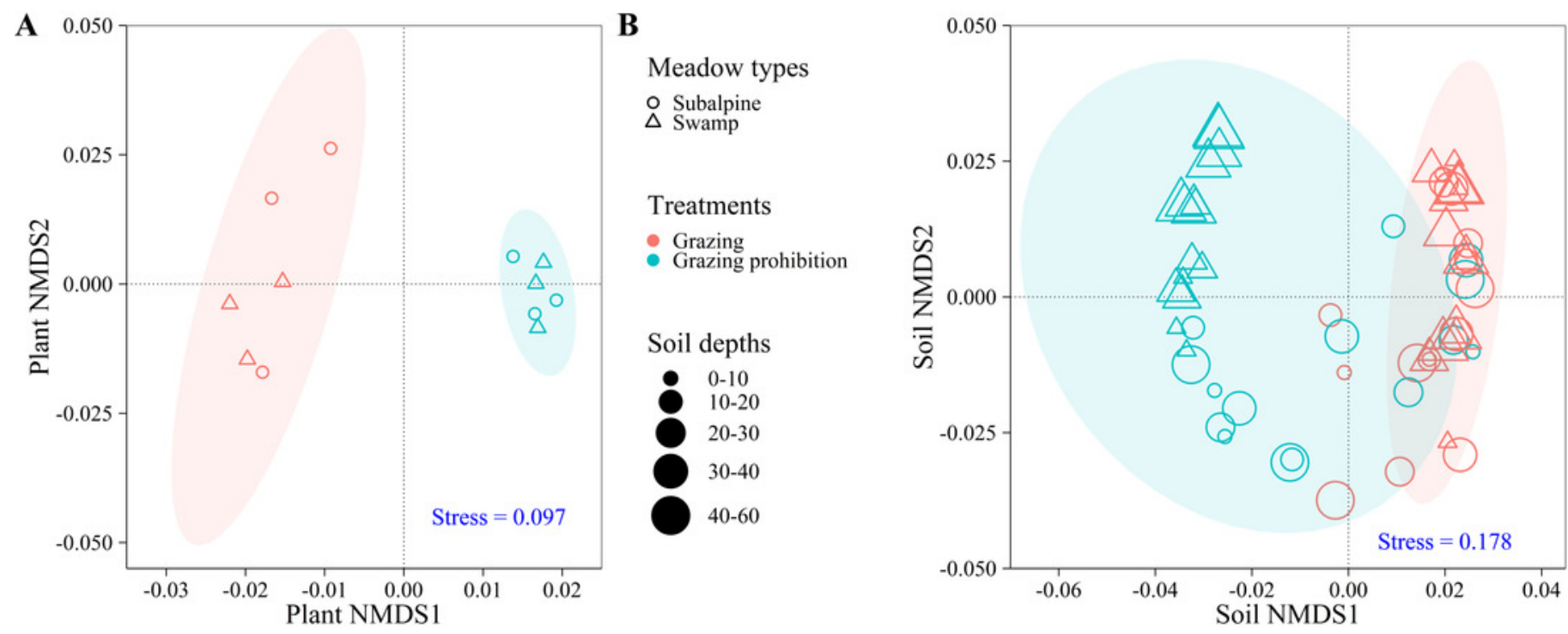
Figure 4

Changes of $\mathrm{pH}$ and soil bulk density with soil depth in subalpine meadow and swamp meadow between grazing and grazing prohibition treatment.

Changes of $\mathrm{pH}(\mathrm{A})$ and soil bulk density $(\mathrm{B})$ with soil depth in subalpine meadow and swamp meadow between grazing and grazing prohibition treatment. Signifificant differences between grazing and grazing prohibition treatment are indicated by symbols: $* * * p<0.001$, ${ }^{* *} p<0.01, * p<0.05 ;$ and no symbol, no signifificant difference.
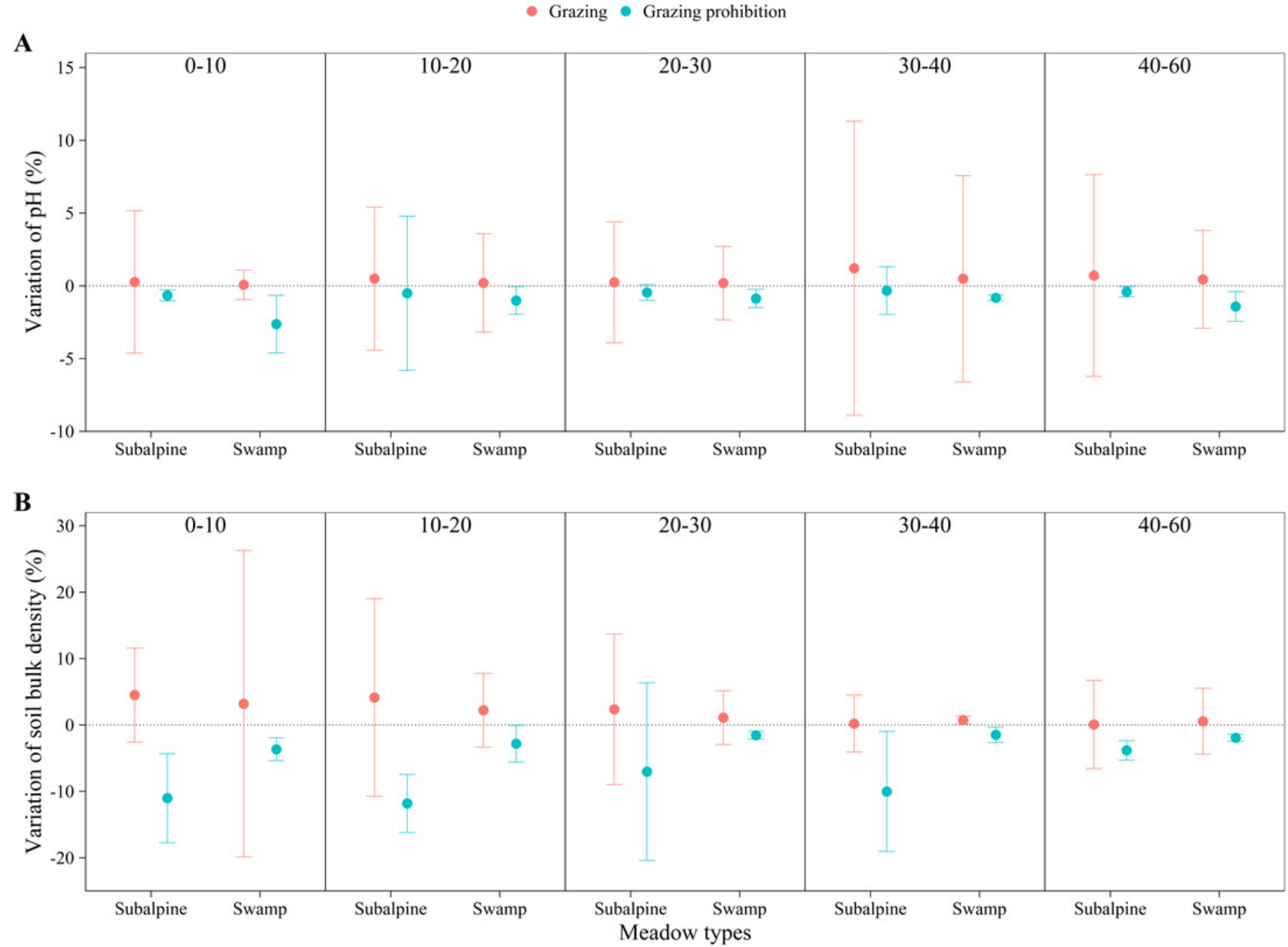
Figure 5

Changes of soil total carbon and soil organic carbon with soil depth in subalpine meadow and swamp meadow between grazing and grazing prohibition treatment.

Changes of soil total carbon (A) and soil organic carbon (B) with soil depth in subalpine meadow and swamp meadow between grazing and grazing prohibition treatment.

Signifificant differences between grazing and grazing prohibition treatment are indicated by symbols: ${ }^{* * *} p<0.001,{ }^{* *} p<0.01, * p<0.05$; and no symbol, no signifificant difference.
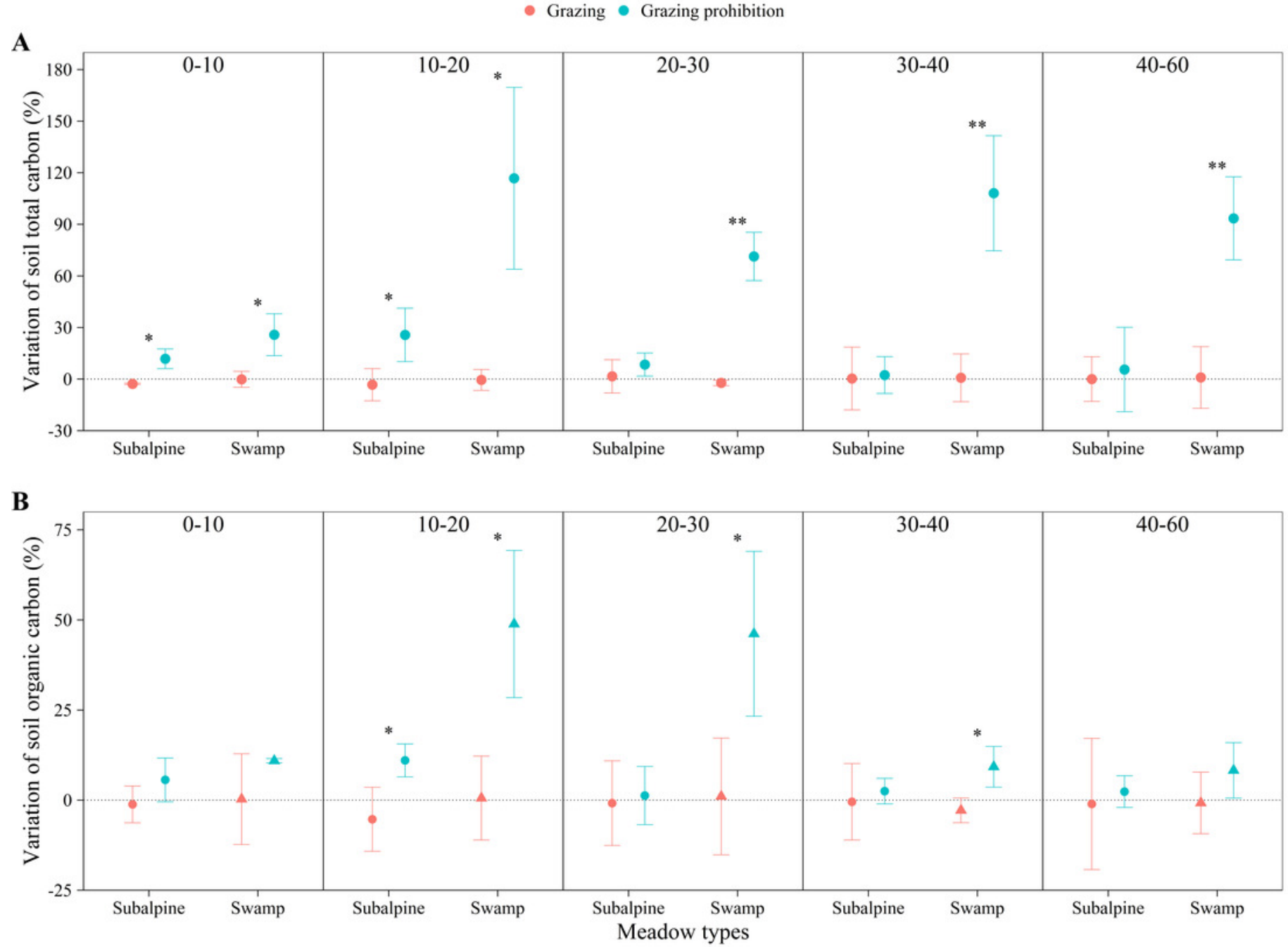
Figure 6

Changes of soil total nitrogen and soil hydrolyzable nitrogen with soil depth in subalpine meadow and swamp meadow between grazing and grazing prohibition treatment.

Changes of soil total nitrogen (A) and soil hydrolyzable nitrogen (B) with soil depth in subalpine meadow and swamp meadow between grazing and grazing prohibition treatment. Signifificant differences between grazing and grazing prohibition treatment are indicated by symbols: ${ }^{* *} p<0.001,{ }^{* *} p<0.01,{ }^{*} p<0.05$; and no symbol, no signifificant difference.
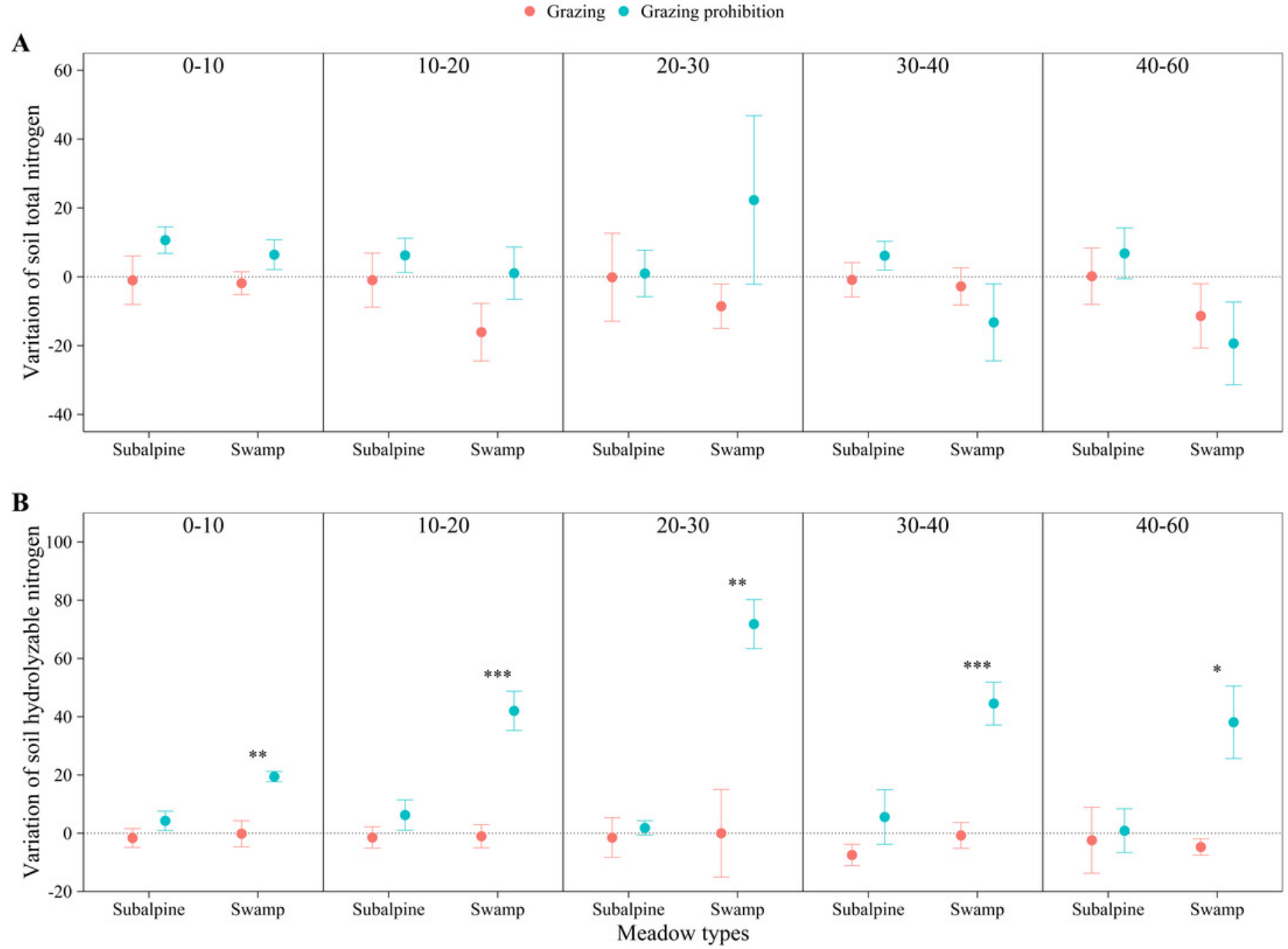
Figure 7

Changes of soil total phosphorus and soil available phosphorus with soil depth in subalpine meadow and swamp meadow between grazing and grazing prohibition treatment.

Changes of soil total phosphorus (A) and soil available phosphorus (B) with soil depth in subalpine meadow and swamp meadow between grazing and grazing prohibition treatment. Signifificant differences between grazing and grazing prohibition treatment are indicated by symbols: ${ }^{* *} p<0.001,{ }^{* *} p<0.01, * p<0.05$; and no symbol, no signifificant difference.

A

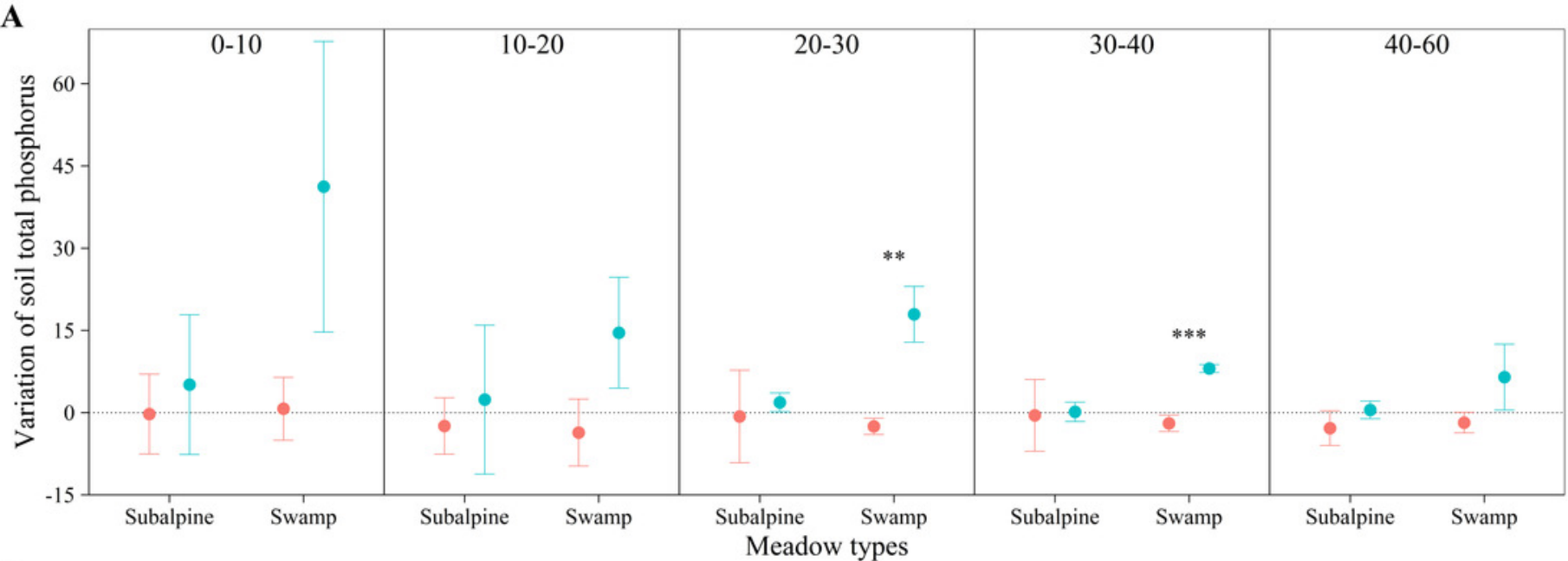

B

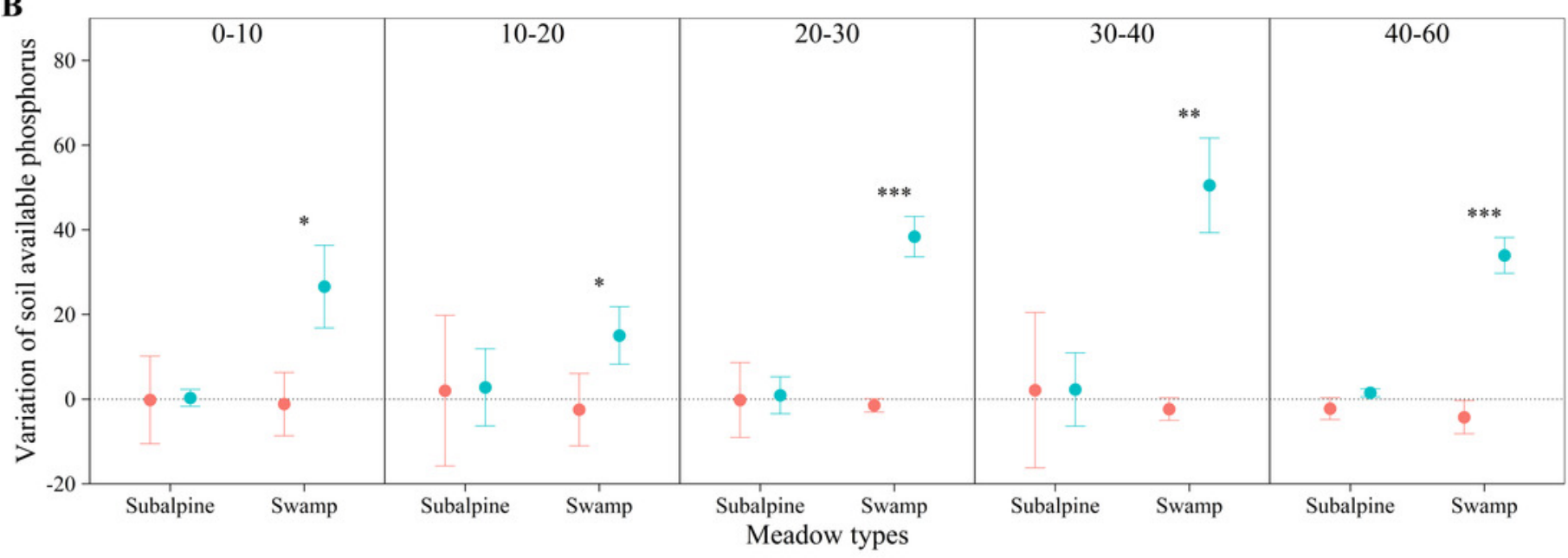

